\title{
Evaluation and management of hemorrhoids: Italian society of colorectal surgery (SICCR) consensus statement
}

\author{
M. Trompetto ${ }^{1}$ - G. Clerico ${ }^{1}$ - G. F. Cocorullo ${ }^{2}$ P. Giordano $^{3}$ - F. Marino ${ }^{4}$.

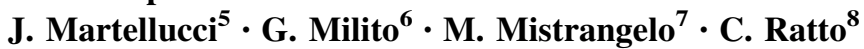

Received: 24 August 2015/Accepted: 5 September 2015/Published online: 24 September 2015

(C) Springer-Verlag Italia Srl 2015

\begin{abstract}
Hemorrhoids are one of the most common medical and surgical diseases and the main reason for a visit to a coloproctologist. This consensus statement was drawn up by the Italian society of colorectal surgery in order to provide practice parameters for an accurate assessment of the disease and consequent appropriate treatment. The authors made a careful search in the main databases (MEDLINE, PubMed, Embase and Cochrane), and all results were classified on the basis of the grade of recommendation $(\mathrm{A}-\mathrm{C})$ of the American College of Chest Physicians.
\end{abstract}

Keywords Hemorrhoids · Hemorrhoidectomy

M. Trompetto

trompetto.mario@libero.it

1 Department of Colorectal Surgery, S. Rita Clinic, Vercelli, Italy

2 Unit of Emergency and General Surgery, Department of Surgical Oncological and Stomatological Sciences, University of Palermo, Palermo, Italy

3 Department of Colorectal Surgery, Barts Health, London, UK

4 Department of General Surgery, “A. Perrino” Hospital, Brindisi, Italy

5 General, Emergency and Minimally Invasive Surgery, Careggi University Hospital, Florence, Italy

6 Department of General Surgery, Tor Vergata University, Rome, Italy

7 Department of General and Minimally Invasive Surgery, University of Turin, Turin, Italy

8 Proctology Unit, University Hospital “A Gemelli”, Catholic University, Rome, Italy
Preoperative evaluation: symptoms, diagnosis, and classification

\section{Symptoms of hemorrhoids}

The commonest symptom of hemorrhoidal disease is painless rectal bleeding. Hemorrhoids appear to be the most common cause of minimal bright red bleeding per rectum or hematochezia [1-4], while they are the second most frequent cause of severe acute lower gastrointestinal bleeding after diverticulosis [5, 6]. Other symptoms may be prolapse, mucous discharge, itching, and feeling of a lump. Thrombosis of external hemorrhoids is responsible for acute anal pain even without bowel movements.

\section{Hemorrhoidal disease classification}

The usefulness of a classification of hemorrhoids stems from the need to choose the most suitable treatment and to have shared parameters for scientific studies.

Hemorrhoids are usually classified on the basis of their location and on the presence and severity of prolapse.

Regarding location, it is appropriate to make a distinction between internal and external hemorrhoids: Internal hemorrhoids arise above the dentate line and are topped with mucosa, while external hemorrhoids arise below the dentate line and are covered by squamous epithelium.

The most widely accepted classification is the Goligher classification [7]: bleeding but no prolapse (grade I)

Hemorrhoidal piles prolapse through the anus during straining but they reduce spontaneously (grade II) Hemorrhoidal piles prolapse through the anus during straining and require manual reduction (grade III) The prolapse is irreducible (grade IV) 
Due to limitations in the Goligher classification that does not consider specific clinical conditions such as circumferential prolapse and possible complications such as thrombosis and due to the need for classification to evolve in step with new technologies for the treatment of hemorrhoidal disease, some authors have proposed new classification systems [8, 9]. However, these are not widely used, perhaps because of their complexity.

\section{Diagnosis of hemorrhoidal disease}

Diagnosis of hemorrhoids should start with a medical history, with great care taken to identify symptoms suggestive of hemorrhoidal disease and risk factors like constipation, followed by physical examination.

Physical examination should include an abdominal examination, inspection of the perianal tissues, anorectal digital examination, and anoscopy.

Even if hemorrhoids are seen on examination, patients with colorectal symptoms should undergo colonoscopy to rule out other abnormalities (grade of recommendation: $B$ ).

In low-risk patients under 50 years of age, flexible sigmoidoscopy may prove to constitute appropriate initial investigation (grade of recommendation: $B$ ).

Colonoscopy should be mandatory in older patients and when there is a personal and/or a family history of colorectal neoplasms, inflammatory bowel disease, altered bowel habits, recent significant weight loss, and laboratory findings of iron deficiency anemia (grade of recommendation: $B$ ).

Sigmoidoscopy and colonoscopy should be integrated with anoscopy or videoanoscopy that has proven to have a higher detection rate of perianal pathology (grade of recommendation: $B$ ).

Although an increased maximum resting anal pressure is a common finding in non-prolapsing hemorrhoids [10, 11], manometry is not routinely performed for diagnosis. However, manometry can be useful for planning surgery in cases of recurrence or if a low anal pressure is suspected at physical examination.

Anorectal endosonography is not usually performed for diagnosis of hemorrhoidal disease, but it can be useful for determining whether hemorrhoids are associated with thickening of submucosal tissue and internal and external anal sphincter [12].

\section{Conservative treatment}

Dietary counseling with appropriate intake of fiber and fluids is the first choice in non-operative treatment in patients with mild symptomatic hemorrhoidal disease.
Increased fiber and fluid intake can give some relief in patients with hemorrhoids who have moderate bleeding, pruritus, and prolapse. Constipation and different types of difficult defecation can play an important role in the development of symptomatic hemorrhoidal disease. Regular bowel habits as well as a reduction in the time on the toilet can contribute to a satisfactory control of the disease.

\section{Fiber}

Trials of fiber show a consistent beneficial effect for symptoms and bleeding in the treatment of symptomatic hemorrhoids. All results showed either a trend or a significant difference in favor of the fiber group compared with placebo [13]. (Level of evidence: I; Grade of recommendation: $B$ ).

\section{Phlebotonics}

Phlebotonics demonstrated a statistically significant beneficial effect on bleeding hemorrhoids in comparison with a control intervention [14] (Level of evidence: I; Grade of recommendation: $B$ ).

\section{Traditional Chinese medicine}

Traditional Chinese herbs were not proved as useful for stopping bleeding from hemorrhoids in a Cochrane Review [15] (Level of evidence: I; Grade of recommendation: D).

\section{Outpatient treatment}

\section{Rubber band ligation}

Patients with grade I, II, and III hemorrhoids who fail conservative treatment may be treated with outpatient procedures such as banding. (Level of evidence I; Grade of recommendation: $B$ ).

\section{Technique}

This procedure is performed in outpatients and consists of positioning an elastic band above the dentate line to strangulate the piles, leaving an area where an inflammatory process fixes the mucosa to the sub-mucosal tissue, preventing the subsequent development of new hemorrhoidal tissue. Sixty-seven percent of patients required only one treatment session, though the sessions can be repeated until there a complete response. There was a 4-week interval between the sessions [16-20]. 


\section{Indications}

This technique is the most widely used as non-surgical treatment for second- or third-degree hemorrhoids (Goligher classification). The most frequent exclusion criteria are first- and fourth-degree hemorrhoids, thrombosed hemorrhoids, anorectal pathologies such as fissures, fistulas, and abscess, colitis, colorectal malignancies, pregnancy, immunodeficiency, diabetes mellitus, and coagulation disorders.

\section{Complications}

The possible minor complications of the technique are pain, bleeding, thrombosis, skin tags, and prolapse [20-23]. Major complications include massive gastroenteric hemorrhage [24] liver abscesses [25], endocarditis [26], and perineal sepsis resulting in death [27].

\section{Sclerotherapy}

Patients with grade I, II, and III hemorrhoids who fail conservative treatment may be treated with sclerotherapy as outpatients. (Level of evidence I; Grade of recommendation: $B$ ).

\section{Technique}

Many sclerosing agents have been used [28-31]. These lead to the necrosis of hemorrhoidal tissue, thus causing moderate tissue destruction with scarring and subsequent fixation of the submucosa.

\section{Indications}

Sclerotherapy appears effective for treating second-degree hemorrhoids. The reported exclusion criteria for the technique are acute inflammation in the perianal region, hemorrhoidal thrombosis, acute irreducible hemorrhoids; cardiac, hepatic, renal and hematological diseases; pregnant or nursing mothers; hypersensitivity to local anesthetics; previous anal surgery, previous sclerotherapy; or fourth-degree proctocele, fissures, fistulas, prolapse, and other proctological conditions, colorectal neoplasia, fecal incontinence, proctitis, abscess, asthma, allergic predisposition, hypercoagulability, thrombophilia, anticoagulant therapy, hepatitis b virus or hepatitis c virus infection, Crohn's disease or ulcerative colitis, diabetes mellitus.

\section{Results}

An improvement in bleeding was reported in $100 \%$ of patients with second- and third-degree hemorrhoids and complete resolution in $69 \%$ of unselected patients, $52 \%$ in third-degree, and $88 \%$ in first-degree hemorrhoids [28, 32,33 . Resolution of prolapse was reported in $90-100 \%$ of patients with second-degree hemorrhoids.

\section{Complications}

Rare but major include impotence, fatal necrotizing fascitis, and abdominal compartment syndrome following sclerotherapy [34-36].

\section{Infrared coagulation}

Patients with grade I, II, and III hemorrhoids who fail conservative treatment may be treated with infrared coagulation. (Level of evidence I; Grade of recommendation: $B)$.

\section{Technique}

Infrared coagulation consists of a direct application of infrared waves resulting in a necrosis of the protein within the hemorrhoids.

\section{Indications}

It is mostly used in for first- and second-degree hemorrhoids.

\section{Results}

Some studies show results similar to rubber band ligation [37-39].

\section{Complications}

Some studies demonstrated a very high percentage of recurrence or persistence of the disease, particularly in patients with third- and fourth-degree hemorrhoids [37]. Data are insufficient for assessment of the long-term efficacy of the technique.

\section{Transanal hemorrhoidal dearterialization (THD)}

THD appears to be a potential treatment option for secondand third-degree hemorrhoids. Clinical trials and longer follow-up are needed to establish a possible role for this technique [40, 41]. (Level of evidence III; Grade of recommendation B).

Doppler assistance in ligating the hemorrhoidal vessels prior to hemorrhoidal mucopexy may not be necessary. (Level of evidence I; Grade of recommendation B). 
Operative time was significantly longer with the use of Doppler, and the postoperative pain score was significantly higher. More complications and unscheduled postoperative events in the Doppler group were reported with no difference in recurrence rates $[42,43]$.

THD is associated with significantly lesser postoperative pain if compared to stapled hemorrhoidopexy (SH). Both techniques are equally effective in the short term with similar rates of complications and recurrence [44-49]. (Level of evidence I; Grade of recommendation B).

Compared with hemorrhoidectomy, dearterialization with mucopexy resulted in similar postoperative pain and morbidity and a similar 24-month cure rate [50, 51] (Level of evidence II; Grade of recommendation B).

\section{Technique}

Based on the technique described by Morinaga in 1995 [52], this approach aims to correct the underlying pathophysiological mechanisms of the disease, both the hemorrhoidal engorgement and bleeding (by progressive shrinkage of piles) and the prolapse (by scarring fixation, following plication, of elongated and prolapsing rectal mucosa/submucosa to the rectal muscle). Using this technique, a hemorrhoid-sparing operation can be performed, avoiding the excision of any recto-anal tissue.

In the first phase of its application, this procedure provided only the ligation of the hemorrhoidal arteries; however, a quite high recurrence rate was found [53]. More recently, the addition of the "mucopexy" (also called "recto-anal repair") has made possible to effectively treat the muco-hemorrhoidal prolapse, making the indications wider and significantly reducing the recurrence rate.

\section{Indications}

Doppler-guided (DG) THD should be reserved for patients presenting active hemorrhoidal disease despite lifestyle/ diet interventions, drug therapy, and minor office procedures, such as rubber band ligation or sclerotherapy. Indications should be established on the basis of the patient's symptoms and physical findings. If the main complaint is bleeding, this can be addressed by dearterialization alone, ligating the hemorrhoidal arteries along the low rectal circumference. In case of bleeding associated with hemorrhoidal or mucosal prolapse, mucopexy should be added to the dearterialization. In fact, mucopexy can be regarded as an "on-demand" step of the DG-THD procedure, depending also on the location and severity of mucosal prolapse (in terms of its length). The prolapsing hemorrhoidal piles and rectal mucosa must be reducible in order to reach their respective anatomical sites Therefore, fibrosed piles should not be treated with DG-THD. This distinction should be the basis for possible indication for DG-THD in some cases of fourth-degree hemorrhoids to the DG-THD approach as suggested by some papers and guidelines [54].

\section{Complications}

Pain was the most frequently reported postoperative complication following DG-THD, experienced by up to $38 \%$ of operated patients (hemorrhoidal artery ligation (HAL): range $0-38 \%$ of patients; THD: range $0-35 \%$ of patients). However, in the majority of series, the incidence of pain was $<10 \%$. A few papers reported tenesmus following the operation, which was more frequent in patients who underwent mucopexy. Postoperative bleeding was reported in up to $18 \%$ of patients (HAL: range 0.9-18\%; THD: range 0-13\%). Hemorrhoidal thrombosis was observed in up to $8.6 \%$ of patients (HAL: range 2.3-6.7 \%; THD: range 0-8.6 \%), being in the majority of papers $<3 \%$. Anal fissure was considered as a postoperative complication in up to $2.1 \%$ of patients (HAL: range $0.9-2.1 \%$; THD: range $0.6-1.5 \%)$. Urge to defecate is infrequently described as a transient postoperative symptom, possibly related to the tenesmus and the acute inflammatory process. In the literature, there is no mention of any life-threatening complication, nor other morbidity observed after different surgical procedures (i.e., rectovaginal fistula, rectal necrosis, retrorectal hematoma, events needing stoma formation).

In the majority of series, the overall recurrence rate ranged between 3 and $24 \%$ (HAL: 3.3-24\%; THD: 3-20\%). Reoperation, due to the recurrence of symptoms, was necessary in $2.7-22 \%$ of patients (HAL: 2.7-22\%; THD: $4.1-17.8 \%)[55,56]$.

\section{Stapled hemorrhoidopexy}

Stapled hemorrhoidopexy is an effective technique for the treatment of hemorrhoids but carries a significantly higher incidence of recurrence and additional operations compared with conventional hemorrhoidectomy (Level of evidence I; Grade of recommendation: A).

$\mathrm{SH}$ was associated with less operating time, earlier return of bowel function, shorter hospital stay, less pain, with a faster functional recovery with shorter time off work, earlier return to normal activities, and better wound healing when compared to conventional hemorrhoidectomy (Level of evidence I; Grade of recommendation: A).

Both SH and LigaSure hemorrhoidectomy are probably equally valuable techniques in modern hemorrhoid surgery (Level of evidence I; Grade of recommendation: B). 


\section{Technique}

The technique consists of a circumferential rectal mucosectomy which results in lifting of the anorectal mucosa (hemorrhoidopexy), [56, 57], restoring the normal anatomy of the anal canal and enabling the hemorrhoidal cushions to perform their role in continence, as opposed to haemorrhoidectomy techniques that only excise abundant tissues. However, the stapler operation may also influences the blood flow, leading to an improvement in venous reflux [58-61].

\section{Results}

Since the introduction of this procedure, a large number of studies have reported on its safety and efficacy. The shortterm benefits of $\mathrm{SH}$ have clearly been demonstrated in studies on short-term outcomes and reviews [58-61].

Undoubtedly, $\mathrm{SH}$ is quicker to perform and patients experience less postoperative pain, postoperative bleeding, wound complications and constipation, and shorter hospital stay and return to their normal activities earlier. Furthermore, the requirements for non-surgical and surgical reinterventions and the readmission rate were similar following SH and conventional hemorrhoidectomy [61].

Some meta-analyses when looking at long-term outcomes after SH and conventional hemorrhoidectomy found higher recurrence rates following $\mathrm{SH}$ [61-63].

The operating time for SH was significantly longer when compared to LigaSure hemorrhoidectomy. Moreover, the incidence of residual skin tags and prolapse was significantly lower in the LigaSure group than in the SH group. The data also indicated that the incidence of recurrence was significantly lower in the LigaSure group than in the SH group [62, 63].

\section{Complications}

Up to $10 \%$ of the patients in the $\mathrm{SH}$ group can experience some form of procedure related event [61], and minor and major complications have been reported [64, 65].

\section{Excisional hemorrhoidectomy}

Open and closed hemorrhoidectomies are both fairly efficient treatments for hemorrhoids, without serious drawbacks. The closed method has no advantage in postoperative pain reduction, but wounds heal faster, though the risk of wound dehiscence is high [66-68]. (Level of evidence II; Grade of recommendation B).
Treatment with the LigaSure technique results in significantly less immediate postoperative pain, reduced blood loss, and reduced operative time without any adverse effect as regards postoperative complications, convalescence, and incontinence. However, it may not confer any advantage over the conventional operation in terms of postoperative pain, length of hospital stay, or time taken to return to work or normal activities. (Level of evidence II; Grade of recommendation B).

\section{Technique}

Nearly 30 years ago, the technique described by Alan Parks was the better choice for treatment. This technique includes hemorrhoidectomy with preservation of the anal canal mucosa, reducing the surgical wound dimensions and leading to a shorter healing time, as well as less stenosis than with conventional techniques. The surgery was performed with a Y-shaped incision made at the mucocutaneous junction, between the upper mucosa of the anal canal and the anorectal junction, as an inverted racket incision; the vascular pedicle was separated from the mucosa and the sphincter plane, connecting it afterward; the mucosa was closed with a running suture, leaving a small area open in the perianal region for draining.

Closed hemorrhoidectomy (Ferguson operation), the most frequently used and recommended technique in the USA, results in less postoperative pain and rapid wound healing. There are many prospective randomized trials comparing Milligan-Morgan and Ferguson hemorrhoidectomy. Most of them do not demonstrate any superiority of the one technique over the other in term of postoperative pain and complications. It should be noted that a partial breakdown of the anal sutures is likely to occur after the Ferguson procedure in up to $25 \%$ of patients.

Authors who perform open hemorrhoidectomy (Milligan-Morgan operation), widely used in Europe, report similar rates of healing and postoperative pain.

\section{Indications}

Grade III-IV hemorrhoidal prolapse is the most common indication for excisional surgical treatment.

\section{Complications}

Pain following hemorrhoidectomy is a common occurrence, and studies have evaluated the use of LigaSure in hemorrhoidectomy [69-74]. In a Cochrane Review comparing conventional hemorrhoidectomy to LigaSure, there was a trend for less pain and a lower incidence of complications associated with LigaSure, but most results were not significantly different [71]. 
In particular after the Milligan-Morgan technique, anal stenosis and some loss of the sensitive anal mucosa have been reported. Analysis of the long-term results after the Milligan-Morgan and Ferguson techniques has also pointed out an incidence of fecal incontinence of $6 \%$.

\section{Thrombosed external hemorrhoids}

Most patients with thrombosed external hemorrhoids benefit from surgical excision within $72 \mathrm{~h}$ of the onset of symptoms [75-77]. Moreover, symptoms last over 3 weeks with conservative treatment (Level of evidence II; Grade of recommendation: $D$ ).

Although most patients treated conservatively will experience eventual resolution of their symptoms, excision of thrombosed external hemorrhoids results in more rapid symptom resolution, a lower recurrence rate, and longer remission intervals. Most excisions can be safely performed in the office setting, although extensive large thrombosed hemorrhoids and those extending into the anal canal may require a more formal surgical approach in the operating room. The thrombosis should be excised along with overlying skin to leave a wide open wound, rather than simply incised and drained, to reduce the risk of local recurrence. Thrombosed external hemorrhoids seen late, with symptoms improving and the clot already resorbing, may be allowed to resolve without excision [75-77].

\section{Conservative treatment}

Analgesics and stool softeners, flavonoids, topical heparin, nifedipine, and glyceryl trinitrate ointment may be beneficial (Level of evidence II; Grade of recommendation: D).

\section{Surgical treatment}

Most patients with thrombosed external hemorrhoids benefit from surgical excision within $72 \mathrm{~h}$ of the onset of symptoms (Level of evidence I; Grade of recommendation: $B)$.

Stapled hemorrhoidectomy is a feasible treatment for selected patients with an acute hemorrhoidal crisis (Level of evidence III; Grade of recommendation: D).

Heparin treatment was found to significantly improve healing and resolution of acute hemorrhoids, with $91 \%$ of patients on heparin treatment exhibiting more pronounced improvement in condition in all measured symptoms and signs compared with the traditional treatment [78, 79].

Excision allows better results compared to incision or $0.2 \%$ glyceryl trinitrate in reduction in pain, symptoms, recurrences, and number of persistent anal skin tags. No difference in symptoms after 1 month was reported [80]. Outpatient excision under local anesthesia of a thrombosed external hemorrhoid can be safely performed with a low recurrence and complication rate while offering a high level of patient of acceptance and satisfaction [81].

Patients with acute hemorrhoidal crisis may be successfully treated with highly standardized and bioavailable mixture of flavonoids and triterpenes in order to avoid or to delay, invasive procedures (if the acute crisis resolves) [82].

A single injection of botulinum toxin into the anal sphincter seems to be effective in rapidly controlling the pain associated with thrombosed external hemorrhoids and could be an effective conservative treatment for this condition [83].

The use of topical nifedipine is a reliable new option in the conservative treatment of thrombosed external hemorrhoids [84].

Hemorrhoidectomy could be proposed [85]; however, conservative treatment for prolapsed thrombosed internal hemorrhoids is associated with shorter inpatient stay and less anal sphincter damage than with surgical treatment [86].

Stapled hemorrhoidectomy is a feasible treatment for selected patients with an acute hemorrhoidal crisis and has a similar complication rate to that of conventional excisional hemorrhoidectomy. Stapled hemorrhoidectomy is superior as regards postoperative pain, operation time, hospital stay, and return to normal activity. However, older patients with anemia or a prolonged hemorrhoidal crisis are unsuitable for this procedure [87-89].

\section{Hemorrhoids and pregnancy}

Although the exact prevalence of hemorrhoidal disease during pregnancy is unknown, the condition is common, and the prevalence of symptomatic hemorrhoids is higher in pregnant than in non-pregnant women.

Due to its frequent association with constipation and increased endopelvic pressure, pregnancy often brings on hemorrhoids that can even thrombose, requiring specialist treatment. Although conservative treatment, closed hemorrhoidectomy has been successfully performed without risk to the fetus [90].

\section{Conservative treatment}

Rutosides seem to be effective in reducing symptoms of hemorrhoids in pregnant women [91] (Level of evidence I; Grade of recommendation: $B$ ). 


\section{Surgical treatment}

Surgery should be used as last resort because medical treatment is sufficient in almost all cases [92] (Level of evidence IV; Grade of recommendation: D).

\section{Compliance with ethical standards}

Conflict of interest The authors declare that they have no conflict of interest.

Ethical approval All procedures performed in studies involving human participants were in accordance with the ethical standards of the institutional and/or national research comitee and with the 1964 Helsinky declaration and its later amendments or comparable ethical standards.

Informed consent Informed consent was obtained from all participants included in the study.

\section{References}

1. Gralnek IM, Ron-Tal Fisher O, Holub JL, Eisen GM (2013) The role of colonoscopy in evaluating hematochezia: a populationbased study in a large consortium of endoscopy practices. Gastrointest Endosc 77:410-418

2. Nikpour S, Ali Asgari A (2008) Colonoscopic evaluation of minimal rectal bleeding in average-risk patients for colorectal cancer. World J Gastroenterol 14:6536-6540

3. Wong RF, Khosla R, Moore JH, Kuwada SK (2004) Consider colonoscopy for young patients with hematochezia. J Fam Pract 53:879-884

4. Mehanna D, Platell C (2001) Investigating chronic, bright red, rectal bleeding. ANZ J Surg 71:720-722

5. Gayer C, Chino A, Lucas C et al (2009) Acute lower gastrointestinal bleeding in 1.112 patients admitted to an urban emergency medical center. Surgery 146:600-606

6. Newman J, Fitzgerald JE, Gupta S, von Roon AC, Sigurdsson HH, Allen-Mersh TG (2012) Outcome predictors in acute surgical admissions for lower gastrointestinal bleeding. Colorectal Dis 14:1020-1026

7. Goligher JC, Duthie HL, Nixon HH (1984) Surgery of the anus, rectum and colon, vol 5. Baillière Tindall, London, pp 98-149

8. Lunniss PJ, Mann CV (2004) Classification of internal haemorrhoids: a discussion paper. Colorectal Dis 6:226-232

9. Gaj F, Trecca A (2007) New "PATE 2006" system for classifying hemorrhoidal disease: advantages resulting from revision of "PATE 2000 Sorrento". Chir Ital 59:521-526

10. Chauhan A, Thomas S, Bishnoi PK, Hadke NS (2007) Randomized controlled trial to assess the role of raised anal pressures in the pathogenesis of symptomatic early hemorrhoids. Dig Surg 24:28-32

11. Sun WM, Read NW, Shorthouse AJ (1990) Hypertensive anal cushions as a cause of the high anal canal pressures in patients with haemorrhoids. Br J Surg 77:458-462

12. Poen Felt-Bersma RJ, Cuesta Meuwissen (1999) Anal endosonography in haemorrhoidal disease: do anatomical changes have clinical implications? Colorectal Dis 1:146-150

13. Alonso-Coello P, Guyatt G, Heels-Andsell D et al (2006) Fiber for the treatment of hamorrhoidal complications: a systematic review and metanalysis. Am J Gastroenterol 101:181-188

14. Perera N, Liolitsa D, Iype S et al (2012) Phlebotonics for haemorrhoids. Cochrane Database Syst Rev 15:CD004322
15. Gan T, Liu YD, Wang Y, Yang J (2010) Traditional Chinese medicine herbs for stopping bleeding from haemorrhoids. Cochrane Database Syst Rev 6:CD006791

16. Awad AE (2012) A prospective randomized comparative study of endoscopic band ligation versus injection sclerotherapy of bleeding internal haemorrhoids in patients with liver cirrhosis. Arab J Gastroenterol 13:77-81

17. Forlini A, Manzelli A, Quaresima S, Forlini M (2009) Long-term results after rubber band ligation for haemorrhoids. Int $\mathrm{J}$ Colorectal Dis 24:1007-1010

18. Kanellos I, Goulimaris I, Christoforidis E, Kelpis T, Betsis D (2003) A comparison of the simultaneous application of sclerotherapy and rubber band ligation, with sclerotherapy and rbl applied separately for the treatment of haemorrhoids: a prospective randomized trial. Colorectal Dis 5:133-138

19. Fukuda A, KIajiyama T, Arakawa H et al (2004) Retroflexed endoscopic multiple band ligation of symptomatic internal haemorrhoids. Gastrointest Endosc 59:380-384

20. Bernal JC, Enquis M, Lopez Garcia J, Garcia Romero J, Trullenque Peris R (2005) Rubber-band ligation for haemorrhoids in a colorectal unit: a prospective study. Rev Esp Enferm Dig 97:38-45

21. Gupta PJ, Heda PS, Kalaskar S (2009) Randomized controlled study between suture ligation and radio wave ablation and suture ligation of grade III symptomatic haemorrhoidal disease. Int J Colorectal Dis 7:223-227

22. Iyer VS, Shrier I, Gordon PH (2004) Long-term outcome of rubber band ligation for symptomatic primary and recurrent internal haemorrhoids. Dis Colon Rectum 47:1364-1370

23. Wehrmann T, Riphaus A, Feinstein J, Stergiuou N (2004) Hemorrhoidal elastic band ligation with flexible videoendoscopes: a prospective randomized comparison with the conventional technique that uses rigid proctoscopes. Gastrointest Endosc 60:191-195

24. Beattie GC, Rao MM, Campbell WJ (2006) Secondary haemorrhage after rubber band ligation of haemorrhoids in patients taking clopidogrel. A cautionary note. Colorectal Dis 8:56-61

25. Chau NG, Bathia S, Raman M (2007) Pylephlebitis and pyogenic liver abscesses: a complication of haemorrhoidal banding. Can J Gastroenterol 21:601-603

26. Tejirian T, Abbas MA (2006) Bacterial endocarditis following rubber band ligation in a patient with ventricular septal defect: report of a case and guide line analysis. Dis Colon Rectum 49:1931-1933

27. Sim HL, Tan KY, Poon PL, Cheng A, Mak K (2009) Lifethreatening perineal sepsis after rubber band ligation of haemorrhoids. Tech Coloproctol 13:161-164

28. Yano T, Asano M, Tanaka S, Oda N, Matsuda Y (2014) Prospective study comparing the new sclerotherapy and hemorrhoidectoy in terms of therapeutic outcomes at 4 years after treatment. Surg Today 44:449-453

29. Miyamoto H, Asanoma M, Mijamoto H, Shimada M (2012) ALTA injection sclerosing therapy. Non excisional treatment of internal haemorrhoids. Hapatogastroenterology 59:77-78

30. Tokunaga Y, Sasaky H (2013) Impact of less invasive treatments including sclerotherapy with a new agent and hemorrhoidopexy for prolapsing internal haemorrhoids. Int Surg 98:210-213

31. Moser KH, Mosch C, Walgenbach M et al (2013) Efficacy and safety of sclerotherapy with polidocanol foam in comparison with fluid sclerosant in the treatment of first grade haemorrhoidal disease. A randomized, controlled, single blind multicentre trial. Int J Colorectal Dis 28:1439-1447

32. Takano M, Iwadare J, Ohba $\mathrm{H}$ et al (2006) Sclerosing therapy of internal haemorrhoids with a novel sclerosing agent. Comparison with ligation and excision. Int J Colorectal Dis 21:44-51 
33. Yano T, Nagaki T, Asano M, Tanaka S, Kawakami K, Matsuda J (2013) Outcome of case-matched injection scleroteraphy with a new agent for haemorrhoids in patients treated with or without blood thinners. Surg Today 43:854-858

34. Bullock N (1997) Impotence after sclerotherapy of hemorrhoids: case reports. BMJ 314:419

35. Schulte T, Fandrich F, Kahlke V (2008) Life-threatening rectal necrosis after injection sclerotherapy for haemorrhoids. Int $\mathbf{J}$ Colorectal Dis 23:725-726

36. Yang P, Wang YJ, Li F, Sun JB (2011) Hemorrhoid sclerotherapy with the complication of abdominal compartment syndrome: report of a case. Chin Med 124:1919-1920

37. Linares Santiago E, Gòmez Parra M, Mendoza Olivares FJ, Pellicer Bautista FJ, Herrerías Gutiérrez JM (2001) Effectiveness of haemorrhoidal treatment by rubber band ligation and infrared photocoagulation. Rev Esp Enfer Dig 93:238-247

38. Marques CF, Nahas SC, Nahas CS, Sobrado CW Jr, Habr-Gama A, Kiss DR (2006) Early results of the treatment of internal hemorrhoid disease by infrared coagulation and elastic banding: a prospective randomized cross-over trial. Tech Coloproctol 10:312-317

39. Poen AC, Felt-Bersma RJ, Cuesta MA, Devillé W, Meuwissen SG (2000) A Randomized controlled trial of rubber band ligation versus infrared coagulation in the treatment of internal hemorrhoids. Eur J Gastroenterol Hepatol 12:535-539

40. Giordano P, Overton J, Madeddu F, Zaman S, Gravante G (2009) Transanal hemorrhoidal dearterialization: a systematic review. Dis Colon Rectum 52:1665-1671

41. Ratto C, Parello A, Veronese E et al (2015) Doppler-guided transanal haemorrhoidal dearterialization for haemorrhoids: results from a multicentre trial. Colorectal Dis 17:910-919

42. Gupta PJ, Kalaskar S, Taori S, Heda PS (2011) Doppler-guided hemorrhoidal artery ligation does not offer any advantage over suture ligation of grade 3 symptomatic hemorrhoids. Tech Coloproctol 15:439-444

43. Schuurman JP, Borel Rinkes IH, Go PM (2012) Hemorrhoidal artery ligation procedure with or without Doppler transducer in grade II and III hemorrhoidal disease: a blinded randomized clinical trial. Ann Surg 255:840-845

44. Sajid MS, Parampalli U, Whitehouse P, Sains P, McFall MR, Baig MK (2012) A systematic review comparing transanal haemorrhoidal de-arterialisation to stapled haemorrhoidopexy in the management of haemorrhoidal disease. Tech Coloproctol 16:1-8

45. Festen S, van Hoogstraten MJ, van Geloven AA, Gerhards MF (2009) Treatment of grade III and IV haemorrhoidal disease with PPH or THD. A randomized trial on postoperative complications and short-term results. Int J Colorectal Dis 24:1401-1405

46. Giordano P, Nastro P, Davies A, Gravante G (2011) Prospective evaluation of stapled haemorrhoidopexy versus transanal haemorrhoidal dearterialisation for stage II and III haemorrhoids: 3-year outcomes. Tech Coloproctol 15:67-73

47. Infantino A, Altomare DF, Bottini C, THD group of the SICCR (Italian Society of Colorectal Surgery) (2012) Prospective randomized multicentre study comparing stapler haemorrhoidopexy with Doppler-guided transanal haemorrhoid dearterialization for third-degree haemorrhoids. Colorectal Dis 14:205-211

48. Tsang YP, Fok KL, Cheung YS, Li KW, Tang CN (2014) Comparison of transanal haemorrhoidal dearterialisation and stapled haemorrhoidopexy in management of haemorrhoidal disease: a retrospective study and literature review. Tech Coloproctol 18:1017-1022

49. De Nardi P, Capretti G, Corsaro A, Staudacher C (2014) A prospective, randomized trial comparing the short- and long-term results of doppler-guided transanal hemorrhoid dearterialization with mucopexy versus excision hemorrhoidectomy for grade III hemorrhoids. Dis Colon Rectum 57:348-353
50. Denoya PI, Fakhoury M, Chang K, Fakhoury J, Bergamaschi R (2013) Dearterialization with mucopexy versus haemorrhoidectomy for grade III or IV haemorrhoids: short-term results of a doubleblind randomized controlled trial. Colorectal Dis 15:1281-1288

51. Elmér SE, Nygren JO, Lenander CE (2013) A randomized trial of transanal hemorrhoidal dearterialization with anopexy compared with open hemorrhoidectomy in the treatment of hemorrhoids. Dis Colon Rectum 56:484-490

52. Morinaga K, Hasuda K, Ikeda T (1995) A novel therapy for internal hemorrhoids: ligation of the hemorrhoidal artery with a newly devised instrument (Moricorn) in conjunction with a Doppler flowmeter. Am J Gastroenterol 90:610-613

53. Dal Monte PP, Tagariello C, Sarago M et al (2007) Transanal haemorrhoidal dearterialisation: nonexcisional surgery for the treatment of haemorrhoidal disease. Tech Coloproctol 11:333-338

54. Ratto C, Giordano P, Donisi L, Parello A, Litta F, Doglietto GB (2011) Transanal haemorrhoidal dearterialization (THD) for selected fourth-degree haemorrhoids. Tech Coloproctol 15:191-197

55. Giordano P, Tomasi I, Pascariello A, Mills E, Elahi S (2014) Transanal dearterialization with targeted mucopexy is effective for advanced haemorrhoids. Colorectal Dis 16:373-376

56. Pescatori M, Favetta U, Dedola S, Orsini S (1997) Transanal stapled excision of rectal mucosa prolapse. Tech Coloproctol 1:96-98

57. Longo A (1998) Treatment of haemorrhoidal disease by reduction of mucosa and haemorrhoidal prolapse with a circular suturing device: a new procedure. In: Proceedings of the 6th world congress of endoscopic surgery, Monduzzi Editore, Bologna, pp 777-784

58. Nisar PJ, Acheson AG, Neal KR, Scholefield JH (2004) Stapled hemorrhoidopexy compared with conventional hemorrhoidectomy: systematic review of randomized, controlled trials. Dis Colon Rectum 47:1837-1845

59. Tjandra JJ, Chan MK (2007) Systematic review on the procedure for prolapse and hemorrhoids (stapled hemorrhoidopexy). Dis Colon Rectum 50:878-892

60. Jayaraman S, Colquhoun PH, Malthaner RA (2006) Stapled versus conventional surgery for hemorrhoids. Cochrane Database Syst Rev 4:CD005393

61. Giordano P, Gravante G, Sorge R, Ovens L, Nastro P (2009) Long-term outcomes of stapled hemorrhoidopexy vs conventional hemorrhoidectomy: a meta-analysis of randomized controlled trials. Arch Surg 144:266-272

62. Chen HL, Woo XB, Cui J, Chen CQ, Peng JS (2014) Ligasure versus stapled hemorrhoidectomy in the treatment of hemorrhoids: a meta-analysis of randomized control trials. Surg Laparosc Endosc Percutan Tech 24:285-289

63. Yang J, Cui PJ, Han HZ, Tong DN (2013) Meta-analysis of stapled hemorrhoidopexy vs LigaSure hemorrhoidectomy. World J Gastroenterol 19:4799-4807

64. Pescatori M, Gagliardi G (2008) Postoperative complications after procedure for prolapsed hemorrhoids (PPH) and stapled transanal rectal resection (STARR) procedures. Tech Coloproctol 12:7-19

65. Naldini G (2011) Serious unconventional complications of surgery with stapler for haemorrhoidal prolapse and obstructed defaecation because of rectocoele and rectal intussusception. Colorectal Dis 13:323-327

66. Arbman G, Krook H, Haapaniemi S (2000) Closed versus open hemorrhoidectomy-is there any difference? Dis Colon Rectum 43:31-34

67. You SY, Kim SH, Chung CS, Lee DK (2005) Open versus closed hemorrhoidectomy. Dis Colon Rectum 48:108-113 
68. Gençosmanoğlu R, Sad O, Koç D, Inceoğlu R (2002) Hemorrhoidectomy: open or closed technique? A prospective, randomized clinical trial. Dis Colon Rectum 45:70-75

69. Fareed M, El-Awady S, Abd-El Monaem H, Aly H (2009) Randomized trial comparing LigaSure to closed Ferguson hemorrhoidectomy. Tech Coloproctol 13:243-246

70. Tan EK, Cornish J, Darzi AW, Papagrigoriadis S, Tekkis PP (2007) Meta-analysis of short-term outcomes of randomized controlled trials of LigaSure versus conventional hemorrhoidectomy. Arch Surg 142:1209-1218

71. Nienhuijs S, de Hingh I (2009) Conventional versus LigaSure hemorrhoidectomy for patients with symptomatic Hemorrhoids. Cochrane Database Syst Rev 21:CD006761

72. Wang JY, Lu CY, Tsai HL et al (2006) Randomized controlled trial of LigaSure with submucosal dissection versus Ferguson hemorrhoidectomy for prolapsed hemorrhoids. World J Surg 30:462-466

73. Sakr MF (2010) LigaSure versus Milligan-Morgan hemorrhoidectomy: a prospective randomized clinical trial. Tech Coloproctol 14:13-17

74. Milito G, Cadeddu F, Muzi MG, Nigro C, Farinon AM (2010) Haemorrhoidectomy with Ligasure vs conventional excisional techniques: meta-analysis of randomized controlled trials. Colorectal Dis 12:85-93

75. Altomare DF, Roveran A, Pecorella G, Gaj F, Stortini E (2006) The treatment of hemorrhoids: guidelines of the Italian society of colo-rectal surgery. Tech Coloproctol 10:181-186

76. Wald A, Bharucha AE, Cosman BC, Whitehead WE (2014) ACG clinical guideline: management of benign anorectal disorders. Am J Gastroenterol 109:1141-1157

77. Rivadeneira DE, Steele SR, Ternent C, Chalasani S, Buie WD, Rafferty JL, Standards Practice Task Force of The American Society of Colon and Rectal Surgeons (2011) Practice parameters for the management of hemorrhoids (revised 2010). Dis Colon Rectum 54:1059-1064

78. Ng L, Monagle K, Monagle P, Newall F, Ignjatovic V (2015) Topical use of antithrombotics: review of literature. Thromb Res 135:575-581

79. Gupta PJ (2002) Use of enzyme and heparin paste in acute haemorrhoids. Rom J Gastroenterol 11:191-195

80. Čavčić J, Turčić J, Martinac P, Mestrović T, Mladina R, Pezerović-Panijan R (2001) Comparison of topically applied $0.2 \%$ glyceryl trinitrate ointment incision and excision in the treatment of perianal thrombosis. Dig Liv Dis 33:335-340

81. Jongen J, Bach S, Stübinger SH, Bock J-U (2003) Excision of thrombosed external hemorrhoid under local anesthesia. A retrospective evaluation of 340 patients. Dis Colon Rectum 46:1226-1231

82. Di Pierro F, Spinelli G, Monsù G et al (2011) Clinical effectiveness of a highly standardized and bioavailable mixture of flavonoids and triterpenes in the management of acute hemorroidal crisis. Acta Biomed 82:35-40

83. Patti R, Arcara M, Bonventre S et al (2008) Randomized clinical trial of botulinum toxin injection for pain relief in patients with thrombosed external haemorrhoids. Br J Surg 95:1339-1343

84. Perrotti P, Antropoli C, Molino D, De Stefano G, Antropoli M (2001) Conservative treatment of acute thrombosed external hemorrhoids with topical nifedipine. Dis Colon Rectum 44:405-409

85. Zuber TJ (2002) Hemorrhoidectomy for thrombosed external hemorrhoids. Am Fam Physician 65:1629-1639

86. Allan A, Samad AJ, Mellon A, Marshall T (2006) Prospective randomised study of urgent haemorrhoidectomy compared with non-operative treatment in the management of prolapsed thrombosed internal haemorrhoids. Colorectal Dis 8:41-45

87. Lai H-J, Jao S-W, Su C-C, Lee M-C, Kang J-C (2007) Stapled hemorrhoidectomy versus conventional excision hemorrhoidectomy for acute hemorrhoidal crisis. J Gastrointest Surg 11:1654-1661

88. Wong JCH, Chung CC, Yau KK et al (2008) Stapled technique for acute thrombosed hemorrhoids: a randomized, controlled trial with long-term results. Dis Colon Rectum 51:397-403

89. Brown SR, Ballan K, Ho E, Ho Fams YH, Seow-Choen F (2001) Stapled mucosectomy for acute thrombosed circumferentially prolapsed piles: a prospective randomized comparison with conventional haemorrhoidectomy. Colorectal Dis 3:175-178

90. Saleeby RG, Rosen L, Stasik SJ et al (1991) Haemorrhoidectomy during pregnancy: risk or relief. Dis Colon Rectum 34:260-261

91. Quijano CE, Abalos E (2005) Conservative management of symptomatic and/or complicated haemorrhoids in pregnancy and the puerperium. Cochrane Database Syst Rev 20:CD004077

92. Abramowitz L, Benabderrhamane D, Philip J, Pospait D, Bonin N, Merrouche M (2011) Pathologie hémorroïdaire de la parturiente. Presse Med 40:955-959 